\title{
Study of heat loss: Ramirent rental modules
}

\author{
Kristjan Edula ${ }^{1}$ \\ ${ }^{1}$ Ramirent Modular Factory AS, 75306 Lehmja, Harju County, Estonia
}

\begin{abstract}
Ramirent Modular Factory (RMF) has conducted the study in cooperation with Tallinn University of Technology to measure heat loss and calculate estimated energy consumption and monthly energy cost of common Ramirent rental modules. The need for the study emerged from Ramirent's rental customers who have requested more environmentally friendly modules. This research was initiated to prove the theoretical assumption that the 2 wooden modules included in the study, which were produced by Ramirent Modular Factory, have lower heat loss and lower monthly energy costs per $\mathrm{m}^{2}$, compared to the steel modules. There were 6 different modules included in the study, 2 steel modules with mineral wool insulation, 2 steel modules with polyurethane insulation and 2 wooden modules with mineral wool insulation. The energy consumption was measured between 21.12.2018 -15.05.2019. Exterior and interior climate of the modules was measured during the research. The conclusion is that 2 wooden modules produced by RMF are most energy efficient and have remarkably lower heat loss per $\mathrm{m}^{2}$ than other modules included in the research. The calculated heat loss of a wooden module was in correlation with the energy consumption measurements. The real measured energy consumption of the steel modules was higher than calculated values. Future studies of heat loss are needed to eliminate disturbing factors and considering the use of ventilation aggregate with heat exchanger vs. direct forced air extraction, while maintaining healthy interior climate requirements.
\end{abstract}

\section{Introduction}

This study was commissioned by Ramirent Baltic AS and conducted by Nearly Zero Energy Buildings Research Group from Tallinn University of Technology.

The purpose of the study is to compare how modules produced by Ramirent Modular Factory compare to other module types and to measure the actual energy use of the modules under controlled conditions over a longer period.

\section{Methods}

\subsection{The modules}

In total, heat loss of six common rental modules used in Ramirent Baltic and Finland was measured at Jüri, Ramirent Modular Factory. Modules No.1 (FFA) and No.6 (SHAA, Fig. 1) are wooden modules, produced by Ramirent Modular Factory, all other modules are steel modules. The modules' specifications are shown in Tables 1 through 3 . All the modules were placed in similar climatic conditions. Ventilation openings were sealed as the purpose was to investigate the heat loss of the enclosure structures.

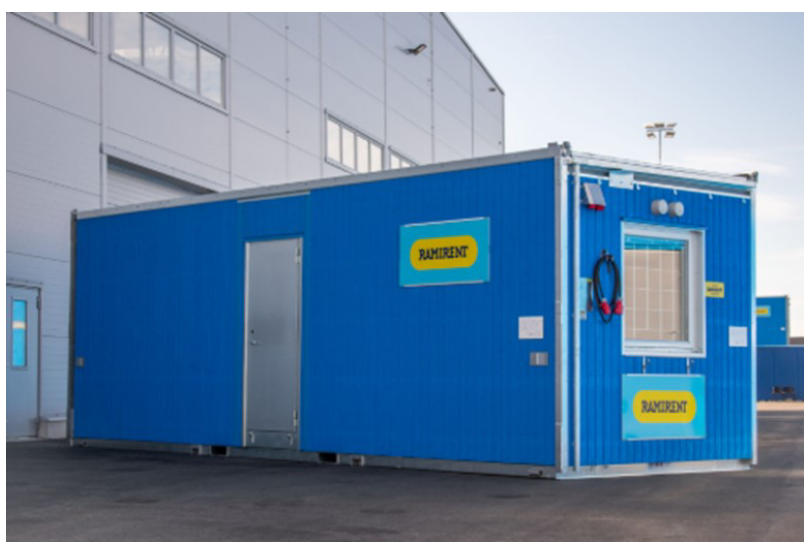

Fig. 1. Module No.6, SHAA

\footnotetext{
${ }^{*}$ Kristjan Edula: kristjan.edula@ramirent.ee
} 
Table 1. Modules specification.

\begin{tabular}{|c|c|c|c|c|}
\hline & Module & $\begin{array}{c}\text { External dimensions, } \\
\text { mm (LxWxH) }\end{array}$ & $\begin{array}{c}\text { Heated } \\
\text { Floor } \\
\text { Area, } \mathrm{m}^{2}\end{array}$ & $\begin{array}{c}\text { Built } \\
\text { (year) }\end{array}$ \\
\hline 1. & FFA & $7226 \times 3442 \times 3000$ & 21.4 & 2018 \\
\hline 2. & PU100 & $6055 \times 2435 \times 2591$ & 13.1 & 2018 \\
\hline 3. & MW100 & $6055 \times 2435 \times 2591$ & 13.1 & 2018 \\
\hline 4. & MW60 & $6055 \times 2435 \times 2591$ & 13.1 & 2017 \\
\hline 5. & PU60 & $7180 \times 3290 \times 3000$ & 20.5 & 2008 \\
\hline 6. & SHAA & $8474 \times 2924 \times 3000$ & 20.5 & 2019 \\
\hline
\end{tabular}

Table 2. Modules insulation. MW- mineral wool, RW- rock wool, PU- polyurethane foam

\begin{tabular}{|c|c|c|c|c|}
\cline { 2 - 5 } & Module & Floor, mm & $\begin{array}{c}\text { Exterior } \\
\text { Wall, } m m\end{array}$ & Roof, mm \\
\hline 1. & FFA & MW150 & MW130 & MW200 \\
\hline 2. & PU100 & PU100 & PU100 & PU140 \\
\hline 3. & MW100 & MW100 & MW100 & PU140 \\
\hline 4. & MW60 & MW100 & MW60 & MW100 \\
\hline 5. & PU60 & PU100 & PU60 & PU100 \\
\hline 6. & SHAA & RW150 & $\begin{array}{c}\text { MW45+ } \\
\text { RW120 }\end{array}$ & $\begin{array}{c}\text { MW50+ } \\
\text { RW170 }\end{array}$ \\
\hline
\end{tabular}

Table 3. Thermal Conductivity of the Module's Envelope Structures $\mathrm{W} /\left(\mathrm{m}^{2} \cdot \mathrm{K}\right)$

\begin{tabular}{|c|c|c|c|c|c|c|}
\hline & Module & Floor & $\begin{array}{c}\text { Ext. } \\
\text { Wall }\end{array}$ & Roof & $\begin{array}{c}\text { Win- } \\
\text { dow }\end{array}$ & Door \\
\hline 1. & FFA & 0.24 & 0.26 & 0.21 & 1.29 & $1.80^{*}$ \\
\hline 2. & PU100 & 0.20 & 0.20 & 0.15 & 1.10 & 1.80 \\
\hline 3. & MW100 & 0.36 & 0.35 & 0.15 & 1.10 & 1.90 \\
\hline 4. & MW60 & 0.36 & 0.57 & 0.36 & 1.10 & 1.90 \\
\hline 5. & PU60 & 0.20 & 0.20 & 0.15 & 1.10 & 1.80 \\
\hline 6. & SHAA & 0.18 & 0.22 & 0.18 & 0.98 & $1.80^{*}$ \\
\hline
\end{tabular}

*Exact value is unknown, estimated value is used in calculations

\subsection{Measurements}

Indoor air and floor surface temperatures of each module were measured, with a data logger Hobo U12-013 Temp/RH/Ext/Ext, Fig. 2.

Outdoor temperature was measured from one module`s north facade. Fig. 3 .

Before the sensors were installed, the sensors were benchmarked and the results differed only $\pm 0,1 \mathrm{C}$, Graph 3.

The whole measurement period lasted 13.12.2018 17.07.2019

Electricity consumption was measured with additional electricity meter installed in each module and an electricity meter in the electrical cabinet, Fig.4. All electric convector heaters were directly connected to the same measuring circuit.

The energy use of the modules was measured over two periods of time:

In the wintertime: $21.12 .2018-11.04 .2019$;

In the springtime: 11.04.2019-15.5.2019.

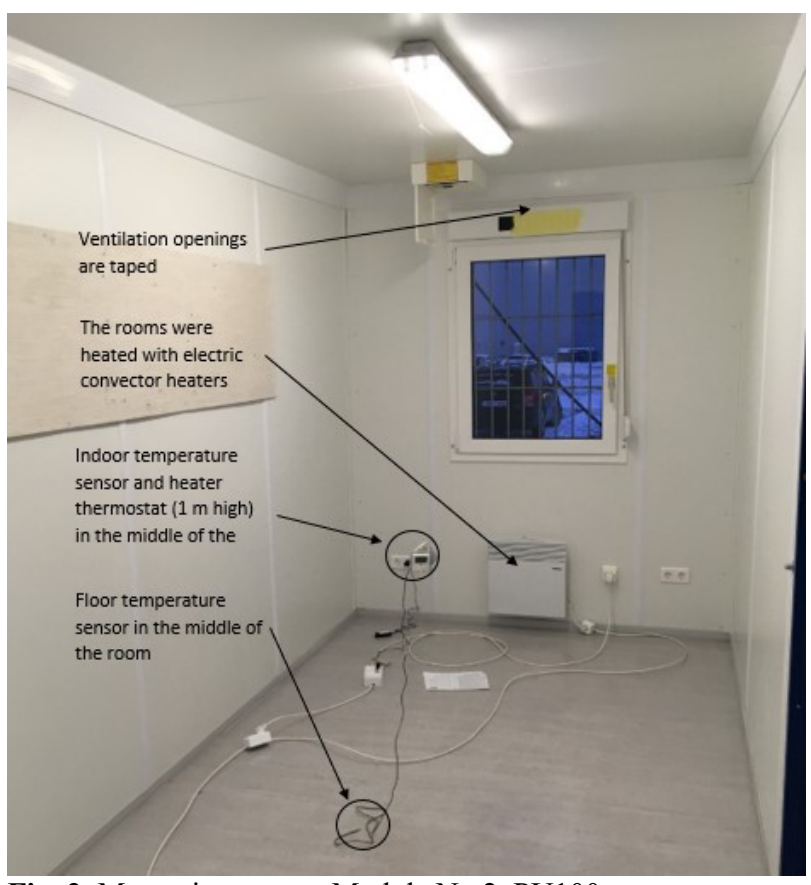

Fig. 2. Measuring set-up, Module No.2, PU100

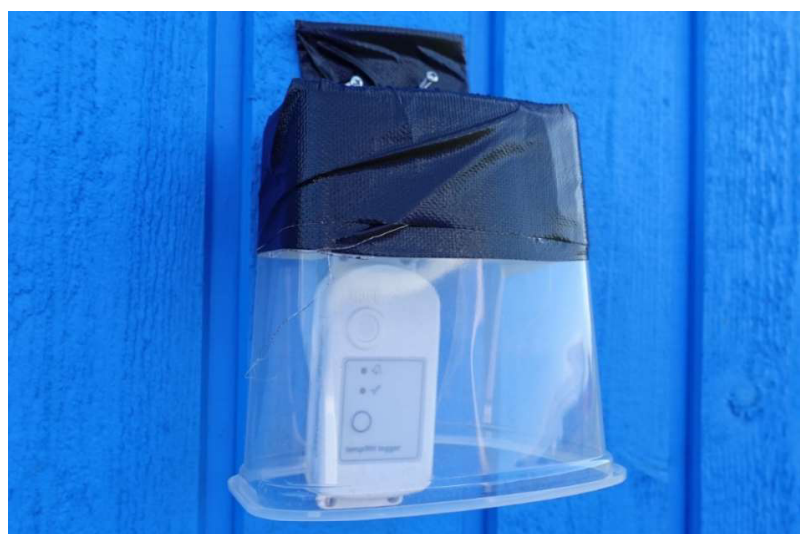

Fig. 3. Measurement of Outdoor Temperature and Humidity 


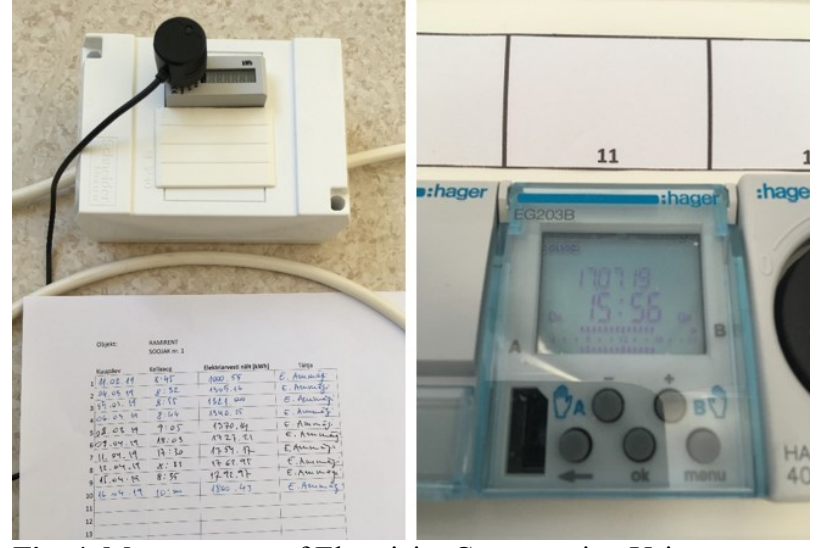

Fig. 4. Measurement of Electricity Consumption Using a Separate Meter (on the left) and a Electricity Meter (on the right) in the Electrical Cabinet

\section{Results}

\subsection{Comparison of measured and calculated heat loss}

Spring heat loss is lower than in winter (Fig. 5), because of the free heat of the sun reduces the need for heating.

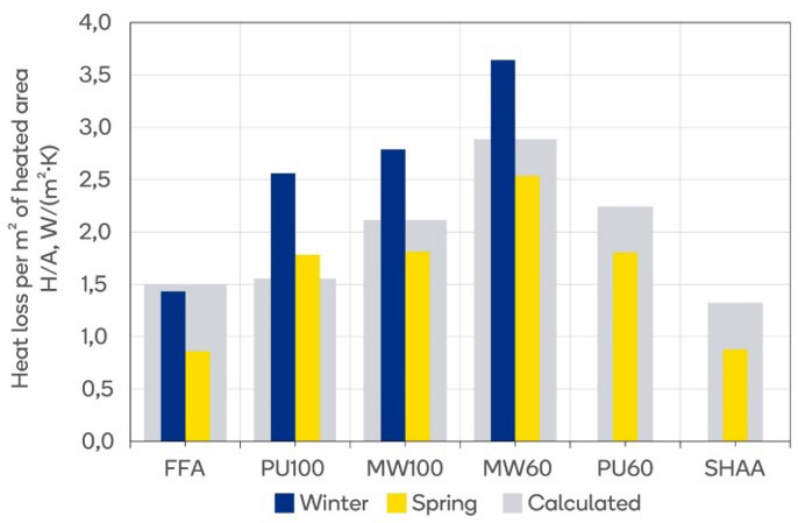

Fig. 5. Heat Loss per $\mathrm{m}^{2}$ of Heated Area

At module 1, the measured heat loss (as it is) in the winter corresponds exactly to the calculated heat loss (how it should be). For modules 2, 3, 4, the calculated heat loss is much better than the result measured. This indicates a higher heat loss in practice. The reasons for increased heat loss may be:

- quality of installation of insulation,

- the declared thermal transmittance is not correctly calculated,

- in practice, greater heat loss through thermal bridges,

- in practice, greater heat loss due to higher air leakage,

After analyses of the results it came out that starting from spring some modules got more sun exposure than the others.

\subsection{Electricity cost}

The cost of heating per $\mathrm{m}^{2}$ of Module No.1 FFA is remarkably lower than compared to other modules, Fig.6.

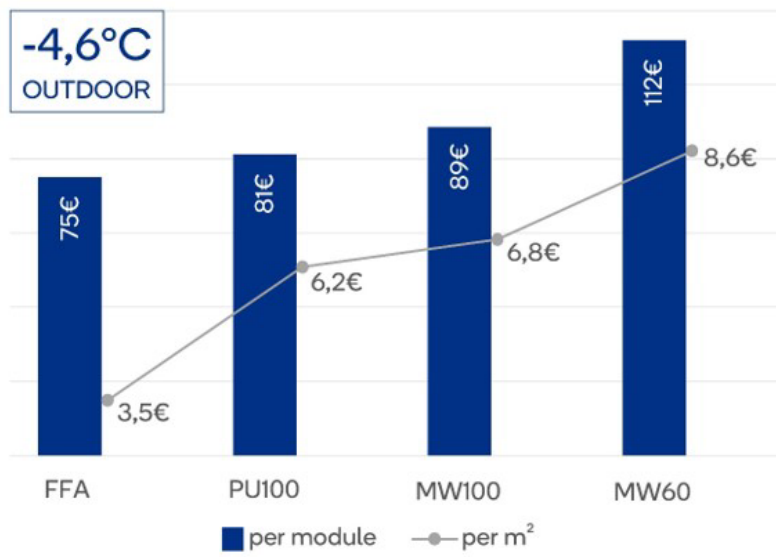

Fig, 6. Electricity Cost for room heating per Module \& per $\mathrm{m}^{2}$ in February

In the Fig. 6 the average electricity for room heating price per kWh is taken from data provided by Eurostat (Statistical Office of the European Union). The average electricity price per $\mathrm{kWh}$ in this study is set at $0.14 €$.

\subsection{Comparison of floor and room temperatures}

The average floor temperature of module No.1 FFA was more than 1.8 degrees higher compared to other modules, Fig. 7.

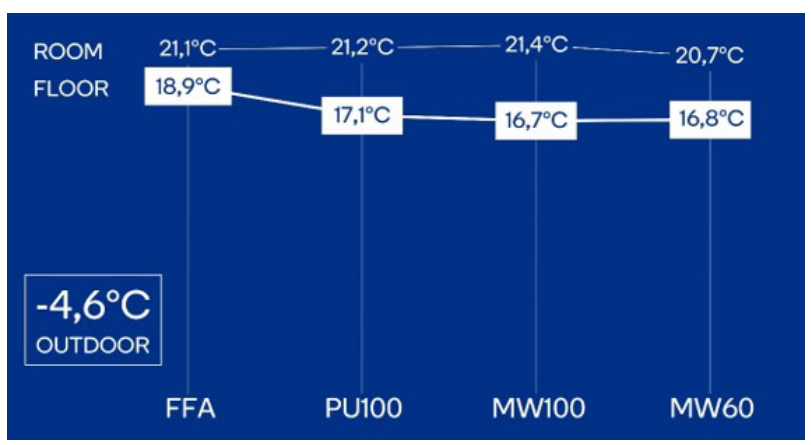

Fig. 7. Average Floor Temperature in February 


\section{Results}

In this study, the indoor climate of the modules was measured for the period of 13.12.2018-17.07.2019 and the energy use for the period 21.12.2018-15.05.2019. In addition to the measurements, the calculated heat loss of the modules was compared with the measurement result.

Based on results of the measurement, modules FFA and SHAA are the most energy efficient.

The calculated heat loss of Module FFA corresponds to the measurement results.

The actual measured heat loss of the modules PU100, MW100 and MW60 is greater than it should be based on computational analysis.

The outcome of the study is affected by various factors. The FFA and MW100 module got partially more sun exposure than other modules. The exterior doors on PU100, MW100 and PU60 modules were not fully airtight (it was discovered in the end of the measurement period), due to bent door blades or wore out rubber door seals. Based on these factors the results could deviate up to $10 \%$.

Future studies of heat loss are needed to eliminate the factors described above. Considering the use of ventilation aggregate with heat exchanger vs. direct forced air extraction, while maintaining healthy interior climate requirements.

\section{References}

1. T. Kalamees, E. Arumägi, 2019. Heat loss study of wooden modules (2019) 